\title{
Bulut Üretim: İşlemler Yönetiminde Yeni Bir Bulut Bilişim Modeli
}

\author{
Cloud Manufacturing: A New Cloud Computing Model in Operations \\ Management
}

\author{
Cansu TAYAKSi' , Erhan ADA², Yiğit KAZANÇOĞLU*
}

\begin{abstract}
ÖZET
Günümüzde gelişen bilgi iletişim teknolojileri ile birlikte işletmelerin yönetim anlayışları ve iş yürütme şekilleri de değişmektedir. Bulut bilişim bu yeni teknolojilerden biri olarak, kurumlara internet üzerinden dinamik bir servis sağlamaktadır. Bulut bilişim ile hizmet her yerden ulaşılabilir, teknolojisi sayesinde talebe göre her an hizmet verilebilir, daha az iletişimle iş akışı yürütülebilir kılınmaktadır. Bir işletme fonksiyonu olarak işlemler yönetimi alanında da benzer gelişmeler gözlenmekte ve bu gelişmelerde büyük ölçüde bilişim hizmetlerinin payı bulunmaktadır. İşlemler Yönetimi alanında ortaya çıkan yeni teknolojilerden birisi de Bulut Hizmet Modeli uygulamalarının bir alt türü olan Bulut Üretim Sistemidir. Bu yeni üretim modeli, işletmeler için daha düşük maliyet, yüksek performans, pazara hızlı girebilme avantajının sağlanması gibi yararları amaçlamaktadır. Bu çalışmada, Bulut Üretim Sistemi'nin kavramsal yapısı, kullanım için gerekli altyapı ve teknoloji ve sağlayacağı avantajlar incelenmiştir. Son olarak, işletmeler için yol haritası olarak kullanılabilecek, mantıksal akışı anlatan yeni bir iş modeli sunulmuştur.
\end{abstract}

Anahtar Kelimeler: Bulut Bilişim, Bulut Üretim, İşlemler Yönetimi

\begin{abstract}
Together with information and communications technology, the concept of management and business conducting has been changing. Cloud computing, as one of those new technologies, gives dynamic services to businesses through the Internet. Cloud Computing makes the service reachable from everywhere, everytime with the pay-as-you-go system. It requires less management effort and workflow could be managed with less communication. As a business function, similar developments has been observed in operations management field. One of the new Technologies is Cloud Manufacturing system which has been developed under Cloud Computing applications. Aim of this new model is providing benefits like lower costs and higher performances, or increasing the market entry speed for businesses. In this study, conceptual structure of Cloud Manufacturing and the advantages has been investigated. Lastly, a business model has been presented that explains the logic flow and can be used as a road map for businesses.
\end{abstract}

Keywords: Cloud Computing, Cloud Manufacturing, Operations Management

sistemler de bu akımlardandır (Bughin, 2010). Bu yeni akımlarla gelen avantajlar kadar dezavantajların da olduğu bir gerçektir. Örnek olarak bu altyapıları kullanmak firmalar için yüksek maliyet oluşturmaya başlamıştır. Büyük ölçekli firmalar bu maliyetlerin altından kalkabiliyorken küçük ve orta ölçekli firmalar için ek işgücü ve finansal kaynak sağlamak sorun teşkil etmektedir, dolayısıyla da rekabetin en üst dereceye tırmandığı dünyamızda varlıklarını sürdürme şansları azalmaktadır. Bulut Bilişim özellikle bu soruna çözüm olarak karşımıza çıkan bir sistem mimarisidir. Firmaların günümüz rekabet dünyasında

\footnotetext{
${ }^{1}$ Arş.Gör., İzmir Ekonomi Üniversitesi, İşletme Bölümü, Sakarya Cad. No:156, Balçova, İzmir 
yer almak için mutlaka bünyelerine katmaları gereken iş çözümlerini hizmet olarak alma şansı kendilerine bulut bilişim sayesinde verilmektedir. Firmaların bu durumda tek yapmaları gereken internet bağlantıları sayesinde servis sağlayıcılarına bağlanmak ve bilişim aygıtları arasında bilgi alışverişini sağlayan bu sisteme katılmaktır. Bulut Bilişim, Uluslararası Standartlar ve Teknoloji Enstitüsüne göre (NIST), "yaygın, kullanışlı, istenildiğinde paylaşılan bir havuzda bulunan bilgi işleme kaynaklarına erişimi sağlayabilecek; hızlı tanımlanabilecek ve en az yönetim gayreti ve hizmettedarikçi ilişkisi içerecek bir modeldir". Bulut bilişimin getirdiği avantajlardan biri de mekandan bağımsız olarak sisteme bağlanabilme ve iş yürütebilme özelliği sağlamasıdır. Bulut kelime anlamıyla hizmetin sağlandığı uzaktaki bir konumu belirtmekte, yani sistem yerel olarak değil de uzaktaki bir sunucuya kurulu bulunmakta ve kullanıcılar istedikleri zaman istedikleri yerden sadece internete bağıı bir bilgisayar sayesinde sisteme bağlanabilmektedirler. Bulut bilişim teknolojilerini kullanarak yazılım ve donanım hizmetlerini dışarıdan alan bir firma teknoloji değiştikçe değişen intiyaçlara tekrar tekrar yatırım yapmaktan kurtulmuş olacak ve yeni hizmetlere ulaşabilmesi için sadece servis sağlayıcı firması ile anlaşmasını yenilemesi yeterli bulunacaktır.

Bulut bilişimin avantajlarının başında düşük donanımveyazılımmaliyetleri,gelişmişperformanstan yararlanabilme (sürekli olarak en yeni teknoloji altyapısına erişme), anında güncellemelerden yararlanabilme, sağlanan yüksek depolama kapasitesi, farklı platformlardan ulaşılabilirliği ve grup çalışmasına uygunluğu gelmektedir. Birçok insan bulut sistemlerin kullanılmasına şüphe ile yaklaşmakta ve veri gizliliğini bir sorun olarak görmektedir. Fakat günümüzde bununla ilgili çalışmalar yapılmaktadır ve veri güvenliği her geçen gün daha üst sınırlara çıkarılmaktadır. Bulut bilişim dezavantajlarından ilki sürekli olarak sabit bir internet bağlantısı bulunması gerekliliğidir. İnternet olmadığında sisteme bağlanılamamakta, yavaş bağlantının olduğu durumlarda ise sistemdeki uygulamalar düzgün olarak çalışmamaktadır. Yukarıda da bahsedildiği gibi bir diğer dezavantaj ise güvenlik açıklarıdır, fakat bunun üzerinde sürekli olarak çalışılmakta ve açıklar giderilmektedir.

Sayılan dezavantajlarına rağmen bilgisayar bilimcilerine göre bulut bilişim internetin geleceği için olmazsa olmazlardandır. Bulut bilişimin gelişmesiyle beraber yeni yapılar ortaya çıkmış ve bu yapılar bulut bilişimi altyapı olarak kullanmaya başlamıştır. Bulut Üretim bunlardan biridir. İnternet kullanımını temel alan bu sistem sayesinde üreticilere üretimle ilgili riskleri azaltma şansı verilmiştir.

Tapscott ve Williams (2008) internet dünyasındaki gelişmelerin ağ odaklı iş birliği modellerinin gelişimine katkısı olduğunu açıklamış ve hiyerarşik iş modellerinden başka modellere kayışı belirtmiştir. Yazarlara göre klasik modeller artık başarılı bir gelişim için sürdürülebilir değillerdir. Kitlesel işbirliklerinin sektörü bir gece içerisinde değiştirebileceği bir dönemde, iş akışını düzenlemek için eski hiyerarşik iş modelleri çeviklik derecesini, yaratıcılığı ve firmaların günümüzde ayakta kalması için gerekli olan bağlantıları sağlayamazlar. Kısacası, sektör klasik iş modellerini işletme süreçleri açısından tekrardan düşünmelidir.

Bu bağlamda yeni bir iş modeli olarak sunulan bulut üretim, günümüzde var olan gelişmiş üretim modellerinden ve bulut bilişim, nesnelerin interneti, sanallaştırma ve hizmet odaklı modeller ve gelişmiş bilgi işleme teknolojileri tarafından desteklenen gelişmiş bilgi teknolojilerinden yola çıkarak oluşturulmuş hizmet odaklı bir üretim modelidir (Tao, 2011).

\section{BULUT BÍLIŞIM VE HIZMET MODELLERi}

Bulut Bilişim, bilişim hizmetlerini, maliyet azaltma ve işletme süreçlerini rahatlatma amacıyla dışarıdan hazır alınabilen bir hizmet haline getirmektedir. Bulut Bilişim sistemlerinde herşey bir hizmet sunumu olarak algılanır (XaaS $-X$ as a Service). Sistemin içinde bulunan hizmet modelleri Hizmet olarak yazılım (SaaS - Software as a Service), Hizmet olarak Platform (PaaS - Platform as a Service) ve Hizmet Olarak Altyapıdır (laaS - Infrastructure as a Service). $\mathrm{Bu}$ hizmetler genelde endüstriyel standartlardaki arayüzler üzerinden sunulmaktadır; Web Hizmetleri, Servis Odaklı Mimari (SOA) (The Open Group, 2010) veya Temsili Durum Transferi Hizmetleri (REST, 2000) bunlardan birkaçıdır. Bahsi geçen hizmetlerin hepsi bulut bilişim sisteminin içinde katmanlar halinde yer alır ve kullanıcılara verilen hizmet gruplarını temsil ederler. En altta bulunan altyapı katmanında (laaS) işlemler, depolama, ağ ve diğer temel bilgi işleme kaynakları standart hizmetler olarak bütün ağa sunulmaktadır. Orta katman olan Hizmet olarak Platform'da (PaaS) ise geliştirme, test etme, yazılımların dağıtımı, barındırma hizmeti, birleştirilmiş geliştirme ortamındaki uygulamaların bakımı için soyutlamalar ve hizmetler yer almaktadır. Hizmet olarak Yazılım (SaaS) katmanında ise kullanıcının kullanmak isteyeceği bütün uygulamalar kullanıma sunulmaktadır. En üstte yer alan kullanıcı arayüzü 
katmanı ise aşağıdaki sistemin bütün katmanlarıyla iletişimi sağlar (Pallis, 2010).

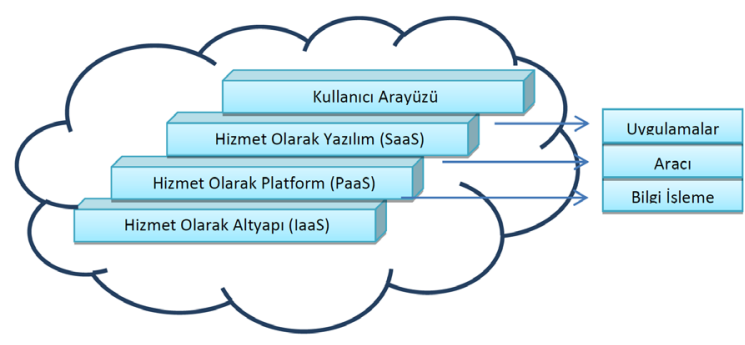

Şekil 1: Herşeyin hizmet olarak sunulduğu Bulut Bilişim Yapısı - XaaS (Xu, 2011)

\subsection{Hizmet Olarak Altyapı (laaS)}

Hizmet olarak Altyapı bazen Hizmet olarak Donanım (HaaS- Hardware as a Service) olarak da adlandırılmaktadır. İsminden de anlaşılabileceği gibi bu hizmet modeli kullanıcılara bilişim teknolojileri altyapısı sağlamaktadır (sunucu, depolama, ağ bileşenleri gibi). Gerekli araç ve gerece servis sağlayıcı sahiptir ve kullanıcıya da sanallaştırmış olarak bu altyapıyı kullanma imkanı verilmektedir. Bu hizmet modelinin en büyük avantajı kullanıcının en son teknolojiye anında ulaşabilme olasılığıdır. Hizmet olarak altyapı modelinde kullanıcılar tedarikçiye kaynak kullanımları kadar ödeme yapmaktadırlar ve bu sayede gereksiz kullanım için bir maliyet oluşmamış olur. Bu model şirketlerin kendi bilgi teknoloji sistemlerini kurmaları ve yönetmeleri için yatırım yapmaları gerekliliğini ortadan kaldırdığından oldukça yararlı görülmektedir (Xu, 2011). Amazon Web Services, AT\&T, HP gibi firmalar ünlü altyapı sağlayıcıları arasındadır.

\subsection{Hizmet Olarak Platform (PaaS)}

Adından da anlaşılabileceği gibi Hizmet olarak Platform, program geliştiricilere, geliştirme süreci, test, dağıtım ve web uygulamalarının barındırma hizmetlerini kapsayan bütün sistem ve ortamları içeren bulut tabanlı bir platform sunmaktadır (Xu, 2011). Bu hizmet sınıfında, kullanıcılar sunulan hizmet havuzundan ihtiyaçlarına göre seçtikleri servis platformunu kullanmaktadırlar. Platform olarak Hizmet' in Altyapı olarak Hizmet' ten farkı fiziksel veya sanallaşstııımış bir altyapı yerine kullanıcıya üzerinde geliştirme yapabileceği işletim sistemi, yazııım programlama ortamları, veri tabanı, web sunucuları gibi platformlar sağlamasıdır. Bu hizmet genelde uygulama geliştiriciler tarafından kullanılmaktadır. Google App Engine, Windows Azure, Amazon Web Services ünlü platform sağlayıcılardan birkaçıdır.

\subsection{Hizmet Olarak Yazılım (SaaS)}

Bazen Hizmet Olarak Uygulama olarak da bilinen bu sınıf türünde kullanıcılara sunulan özel yazııımlar ile lokalde hiçbir işgücü ve bakım maliyeti olmadan yazılımlardan istifade edebilme imkanı sağlanmıştır. SaaS bir yazılım dağıtım modelidir ve son kullanıcılara talep ettikleri yazılımı kullanma imkanı sağlar. Google Apps, salesforce.com, Netsuite gibi örnekler popüler bulut SaaS uygulamaları arasındadır.

Sonuç olarak, laaS ile daha çok sistem uzmanları ve ağ mimarları; PaaS ile uygulama geliştiriciler, SaaS ile de daha çok son kullanıcılar hed ef alınmaktadır.

\section{IŞLEMLER YÖNETIMINDE YENI BIRR MODEL: BULUT ÜRETIM}

Küresel rekabet ve son yıllardaki hızlı teknolojik gelişmeler üretim yapan işletmeleri de sürekli olarak gelişim ve farklılık yaratma zorunluluğuna itmiştir. Bu ortamda varlığını sürdürmek isteyen işletmeler farklılıklarını ortaya koyabilecekleri teknoloji arayışlarına girmişlerdir. Bulut üretim ise, üretim yapan işletmeler için bu arayışa cevap verecek olan, kullanıcılara her zaman her yerden ulaşabilecekleri merkezi bir yönetim imkânı sunan, fakat şu anda kavramsal olarak var olan hizmet odaklı yeni bir teknolojik üretim modelidir. Bu kavram yeni bir hizmet odaklı üretim sistemidir ve bulut bilişim kavramını genişletmektedir (Armbrust vd., 2010). Bu yeni sistemin amacı seri üretim kaynak ve imkânlarını daha geniş bir şekilde birleştirmek ve internet aracılığıyla kullanıcılara sunmaktır (Li vd, 2010). Buna bağlı olarak, bulut üretim kullanan işletmeler kendi taleplerine bağlı olarak hizmet satın alacaklar, dolayısıyla modelin getirdiği şekilde maliyet azaltarak rekabet avantajından yararlanacaklardır.

Bulut üretim modeli kaynağını bulut bilişim teknolojisi ve ağ esaslı üretim modelinden alır. Günümüzün şebeke (ağ) esaslı üretim modeli genel olarak tek bir üretim görevi için dağıtıımış kaynakların birleştirilmesinden oluşmaktadır (Li vd., 2010; Tao vd., 2010). Bulut üretim, üretim kaynaklarını bulut üretim hizmet merkezinde birleştirir. Bu merkezi yönetim ve üretim kaynaklarının işlemleri sayesinde farklı üretim kaynağı sağlama servisleri farklı kullanıcılara sunulabilir (Zhang vd., 2010). Bulut üretim, geliş̧miş üretim modellerinden ( $A S P, A M, N M, M G r i d)$ ve bulut bilişim desteğiyle ilerleyen kurumsal bilgi teknolojileri, Nesnelerin İnterneti (IoT), sanallaştırma ve hizmet-odaklı teknolojiler ve gelişmiş bilgi işleme teknolojilerinden ortaya çıkarak geliştirilmiş bir bilgi işleme ve hizmet odaklı üretim modelidir. (Tao vd., 
2011). 21. Yüzyılın başlarında bulut uygulamaları ve Nesnelerin İnterneti küresel ortamda var olan üretim işletmelerinin gelişimi için sahip olması gereken ana teknolojilerden sayılmıştır (Xu, 2011).

Bulut üretim modeli temel olarak üç bileşenden oluşmaktadır. Bunlar:

1. İhtiyaç doğrultusunda taleplerde bulunan kaynak kullanıcıları,

2. Hizmet olarak fiziksel kaynak sağlayıcılar,

3. İkisinin arasında köprü görevi yapan bulut teknolojisidir.

Tao (2011) tarafından ana olarak 3 kullanıcıdan oluştuğu belirtilen sistem aşağıdaki gibi anlatılmaktadır:

Kaynak Kullanıcı: Bulut üretim hizmet platformuna hizmetlerden yararlanabilmek için kaydolan kullanıcılardır. İhtiyaçları olduğu kadar servisi satan işlem operatörlerinden satın alan kullanıcılar kullanımları kadar ödeme yaparlar.

Tedarikçi: Tedarikçi üretim süreç döngüsü içinde gerekli olan üretim kaynaklarına ve yetkinliğine sahiptir ve tedarik işlemiyle sorumludur. Tedarikçiler bir kişi, bir örgüt, bir kurum veya bir üçüncü parti olabilir.

İşlem Operatörü: Iş̧lem operatörleri, bulut üretim sisteminin hizmet ve fonksiyonlarını kullanıcılar, tedarikçiler ve üçüncü partilere sağlamak üzere sistemi yönetmektedirler. Operatörler; kurumlar, satış işlemleri, lisanslama, üretim bulut sistemleri hakkında danışma ve bu sistemi sağlama, sistem güncellemesi gibi işlemlerle ilgilenmektedirler.

Bulut uygulamalarını yöneten merkezi yönetim ile kullanıcılar tarafından gelen taleplere uygun üretim süreç planlaması ve bu süreçlere uygun fiziksel kaynak tahsis edilmesi sağlanır.

\subsection{Bulut Üretimin Yapısı ve Kullanımı}

Bulut üretimde önemli olan, üretim kaynaklarını hizmet haline dönüştürülüp son kullanıcıya merkezi bir şekilde yönetebilecekleri bir sistem sunmaktır. Xu'nun modeline göre (2011), bulut üretim sistemi dört adet katmandan oluşmuştur. Üretim kaynakları son kullanıcıya doğru giderken, sanal hizmet katmanı ve genel hizmet katmanından geçerek Uygulama Katmanına ulaşır. Bu katmanda kullanıcı kaynakları isteği doğrultusunda yönetebilecektir.

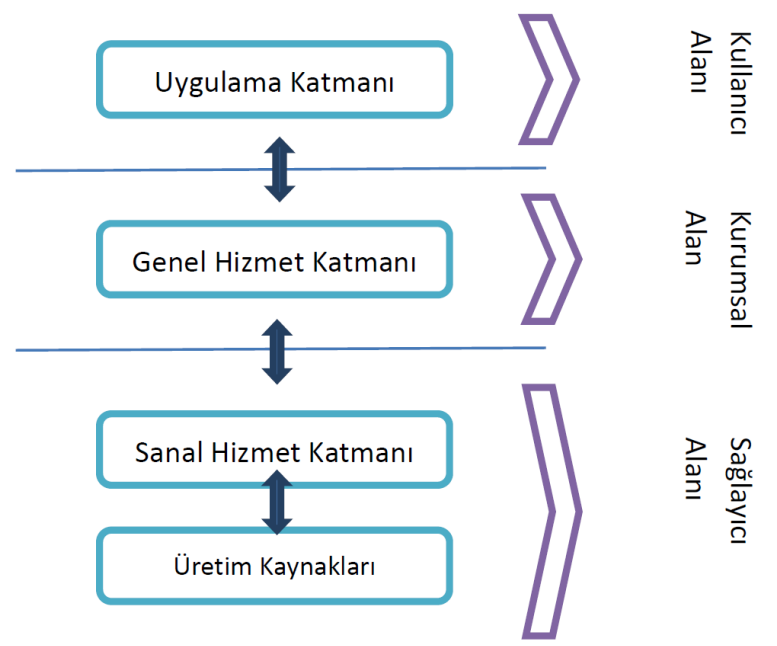

Şekil 2: Bulut Üretimin Sisteminin Katmanları (Xu, 2011)

En alttaki üretim kaynakları katmanı üretim için gerekli olan bütün katmanları sunar. Xu'ya göre (2011) bu kaynaklar iki şekle ayrılmaktadır: Fiziksel ve Fiziksel Olmayan Kaynaklar. Fiziksel kaynakların içinde üretim için gerekli olan donanım, bilgisayarlar, sunucular, ham maddeler, üretim yazılımları, analiz gereçleri, veri, çalışanlar vb. kaynaklar bulunmaktadır. Fiziksel olmayan kaynaklar ise ürün tasarımı, simülasyon gerçekleştirebilme, bilgi birikimi, bakım sunma gibi hizmet kaynaklarını içermektedir.

SanalHizmetkatmanınıntemelde3adetfonksiyonu bulunmaktadır (Xu, 2011). Bunlar sırasılla Üretim kaynaklarının tespiti, Kaynakların sanallaştırılması ve Bulut Üretim Hizmeti haline dönüşecek şekilde paketlemelerinin yapılmasıdır. Kaynakları tespit etme işleminde birden fazla teknolojiden yararlanılabilir: RFID, kablosuz sensör ağları, Nesnelerin İnterneti (IoT), GPS bunlardan birkaçıdır (Huang vd. 2007; Huang vd. 2009). Sanallaştırma ise fiziksel kaynakları mantıksal sanallaştırmaya tabi tutmaktır. Sanal kaynaklar protokoller ve yazılım dilleri aracılığıyla paketler halinde bulut hizmet görevi vermek üzere hazır edilirler.

Genel Hizmet katmanı Kurumsal alanda yer almaktadır. Sanallaştııılmış kaynakların kullanıcıya aktarılmasından sorumlu olan katmandır. Sağlanan kaynağa ve kullanıcının talebine göre hizmet sunulur.

En üst katman olan Uygulama Katmanı kullanıcı ile sistem arasında ara yüz görevi görmektedir. Bu aşamada kullanıcı karşısına gelen sanallaştırılmış kaynakları kullanarak kendi üretim görevini gerçekleştirir. 
Bulut üretim, bulut bilişimden yola çıkan yeni bir kavram olup "hizmet olarak yazılım" "hizmet olarak üretim" kavramına doğru genişlemiştir (Hao vd., 2005). Bulut üretim, bulut bilişimin kavramsal altyapısına ek olarak temel teknoloji altyapısını da kullanmıştır. Bu kaynaklar genelde bilgisayar teknoloji altyapısı kaynaklarıdır. Sunucular, depolama alanları, ağ bağlantıları ve yazılımlar bunlara birer örnek olabilir ve genelde kullanıcıya daha önce de bahsedilen aşağıdaki başlıklardaki yer alan üç adet servis olarak sunulurlar (Tao vd., 2011).

- Hizmet olarak altyapı (laaS)

- Hizmet olarak platform (PaaS)

- Hizmet olarak yazılım (SaaS)

Bulut üretimde, bilişim teknolojisi kaynaklarına ek olarak, üretim döngüsüne dahil olan bütün üretim kaynak ve yetkinlikleri kullanıcıya laaS, PaaS ve SaaS hizmet modelleri üzerine dayandırılarak sunulmaya çalışılır. Aşağıdaki modeller bunlardan birkaçıdır (Tao, 2011):

- Hizmet olarak Tasarım (DaaS): tasarım kaynak ve yetkinlikleri hizmet olarak verilir.

- Hizmet olarak Üretim (MFGaaS):üretim kaynak ve yetkinlikleri hizmet olarak verilir.

- Hizmet olarak Deneyleme (EaaS): deneyleme kaynak ve yetkinlikleri hizmet olarak verilir.

- Hizmet olarak Simulasyon (SIMaaS): simülasyon kaynak ve yetkinlikleri servis olarak verilir.

- Hizmet olarak Yönetim (MaaS): yönetim kaynak ve yetkinlikleri servis olarak verilir.

- Hizmet olarak Bakım (MAaaS): bakım kaynak ve yetkinlikleri servis olarak verilir.

- Hizmet olarak Bütünleştirme (INTaaS): bütünleştirilmiş kaynak ve yetkinlikleri servis olarak verilir.

Sonuç olarak Bulut Üretim Hizmet modellerinin kullanılabilmesi için Bulut Bilişimin altyapı olarak kullanılması zorunludur. Bu altyapı ile yeni hizmet modeli iç içe geçmiş bir model şeklindedir.

\subsection{Bulut Üretimin Faydaları ve Zorlukları}

Bulut üretim kullanımının şirketler için getirdiği faydalar ve bununla birlikte oluşan zorluklar ve kullanımın getirdiği tereddütler mevcuttur. Bu konular aşağıda ayrıntılı şekilde anlatılmıştır.

\subsection{Faydalar}

Operasyon maliyetlerini düşürücü özelliği en önemli faydalardan biridir. Teknoloji altyapısına yapılması gereken yatırımın azalmasıyla birlikte kullanım giderleri azalmıştır. Örnek olarak Müşteri illişkileri Yönetimi programı olarak tasvir ettiğimiz CRM ve Kurumsal Kaynak Planlaması olarak bildiğimiz ERP programları maliyetleri yüksek programlardır. Üretim firmaları ERP programlarını web tabanlı olarak Bulut hizmet sağlayıcılarından alarak maliyetlerini düşürebilirler. Bu durum sayesinde, özellikle KüçükOrta Ölçekli Iş̧letmelerin teknolojiye ayak uydurmaları için gerekli olan yüksek pazara giriş maliyetlerinde düşüş elde edilmiştir.

- Altyapı ve kullanım maliyetine ek olarak yönetim için gerekli olan maliyet de düşmüştür.

- Enerji kullanımından doğan maliyet düşmüştür.

- "Hizmet olarak Yazılım" ilkesini “Hizmet olarak Üretim" şeklinde genişletebiliyor olmakla birlikte, sunulan hizmetlere katma değer eklenmiş, düşük maliyetli, şebeke altyapısıyla çalışan küresel üretim ortamına uyan ürünler piyasaya sunulabilmektedir (Yang, 2010).

- Herhangi bir yerden herhangi bir zamanda üretim sistemini merkezi olarak yönetebilme özelliği sayesinde yöneticilerin tek bir mekanda bulunma zorunluluğu ortadan kalkmıştır.

- Farklı hizmet sağlayıcılardan aynı anda farklı hizmetler alınarak paralel süreç yürütülebilir ve üretim hızı artabilir. Böylece verimlilik artışı gözlenecektir.

- Hizmet sağlayıcılar sadece kendi alanlarında uzmanlaştıkları için, olası bir problemde anında yardım veya gerekli konular hakkında veri analizi alınabilecektir. Ayrıca teknoloji için gereken bakım maliyeti hizmet verici firma tarafından karşılandığından hizmeti kullanan firmalarda bakım maliyeti söz konusu olmayacaktır.

- Yatırım maliyetinde düşüş sağladığı için firmaların gerekli başka alanlara yatırım yapmak konusunda esneklik kazanacaktır.

- Firmalar üretimi hizmet alımı şekline dönüştürdüklerinde fiziksel kapasite söz konusu olmaktan çıkacak, kapasitelerini satın alabildikleri hizmet oranında genişletebileceklerdir.

\subsubsection{Zorluklar ve Tereddütler}

- Büyük ölçekli bir firmanın yatırım maliyeti konusunda kısıtı olmadığı ve bu noktada maliyet düşürücü özellik önemini yitirdiği 
için Bulut Üretimin sadece Küçük-Orta Ölçekli İşletmeler için olup olmadığı konusunda tereddütler vardır (Epicor, 2013).

- Üretim fonksiyonu çalışanları konu değişikliğe gelince çok tutucu davranabilmektedir.

- Sistem internet bağlantısına bağlı olduğundan dolayı, bağlantı kesildiğinde operasyonlar da kesintiye uğrayabilir.

- Yönetici düzeyinde Bulut Sistemler üzerine aktarılan verinin güvenliğinden endişe duyulmaktadır.

- Köklü sistemler ve modeller açısından kullanılır olmayabilir; kriter ve standartlar açısından eksiklikleri olan bir sistemdir; kişisel, kuruluşsal, ulusal ve uluslararası alanlarda düzenlemeler gerektirmektedir; güvenlik ve güvenilirlik problemi vardır (Tao, 2011)

\section{FARKLI ÜRETIM BULUTLARININ BIRLEŞTIRILIMESi}

Literatürdeki son çalışmalar sadece tek ve izole edilmiş bir üretim bulutunu esas almaktadır (He ve Xu, 2015). Üretim kaynakları, veri ve farklı bulutlardan elde edilen imkânların birleştirilmesi hala araştırmalar açısından güç bir konudur (He ve Xu, 2015; Valilai ve Houshmand, 2013). Bu güçlük farklı sektörel bulutların birleştirilmesini gerektiren akıllı fabrika, akıllı ev, akıllı bina ve akıllı şehir gibi konularda da geçerlidir (Kirkham vd, 2014). Bunun yanı sıra, farklı üretim bulutlarının bir araya getirilmesiyle ilgili çok az çalışma yapılmıştır. Üretim bulutlarının operatörlerinden ve kullanıcılarından gelen talebe göre bu önemli ve araştırılması gereken bir durumdur ve bu konu üzerine daha çok araştırma yapılması gerekmektedir (Yang vd., 2015). Bulut üretimde bir bütünleşme sürecine gidilebilmesi için farklı çalışmalar yapılmaya başlanmıştır. Wang ve Xu (2013) hizmet odaklı, birlikte çalışabilir bir bulut üretim sistemi sunmuştur. Bu bulut tabanlı sistemin içindeki sanal fonksiyon blok mekanizması ve standart tanım şu anda var olan ve gelecekte var olacak olan üretim kaynaklarını birleştirme amaçlı sunulmuştur. Lu, Xu ve Xu (2014) daha sonra şirketlerin işletme hedeflerine uygun olarak farklı şekillerde kullanabileceği bulut kullanım yöntemlerini bütünleştirebilecek bir karma bulut üretim modeli sunmuştur

Bütünleştirme çerçevesi farklı iki hedef için farklı iki bütünleştirme yaklaşımını (Birleştirilmiş Bulut Üretim ve Üçüncü Parti Bulut Üretim) içermektedir (Yang vd., 2015). Birleştirilmiş bulut üretim genel olarak kullanıcıların çıkarlarını maksimize etmek için üretim kaynak ve yetkinliklerinin birleşimi ile ilgileniyor olup, üçüncü parti bulut üretim kullanıcılara en iyi şekilde uyan hizmeti bulmak için onların adına davranışlarda bulunur. Üretim bulutları bütünleştirilmiş bir bulut üretim sistemine ait olabilir veya olmayabilir. Hizmet kullanıcıları platform, yazılım veya uygulamalarını üretim bulutunun içerisinde veya üçüncü parti bulut üretim sayesinde farklı üretim bulutlarında geliştirebilir.
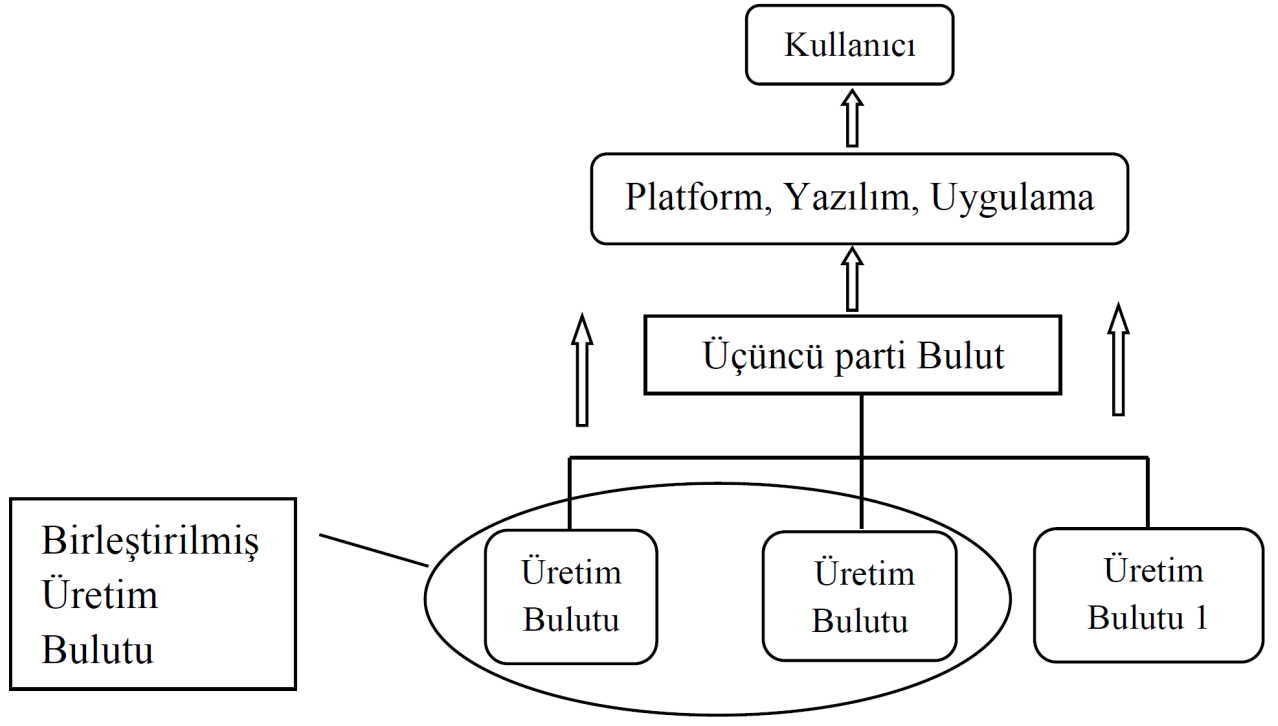

Şekil 3: Birden fazla üretim bulutu için karma bütünleştirme yapısı (Yang vd., 2015) 


\subsection{Birleștirilmiş Bulut Üretimin Özellikleri}

Üretim bulutu operatörleri gönüllü olarak sonsuz üretim kaynak ve imkânlarının olduğunu varsayarak, üretim bulutunun üretim kaynak ve imkanlarını dinamik olarak birbirinden gelen talebe göre üretim kaynak ve imkanlarının yetmemesi durumunun etkisini elimine etmek ve kullanıcı denetimini yüksek derece geliştirmek için birleştirilmiş bulut üretim ortamı kurarlar. Bu şekilde bir bütünleşme, üretim bulutu federasyonunun operasyonlarının sistemli bir şekilde ilerlemesi için ortak bazı kurallar ve standartlar tarafından izlenmelidir. Operatörler üretim bulutlarını işletme hedeflerini ortak kurallara uyarak gerçekleştirme koşuluyla yine kendi özerkliklerinde çalıştırabilirler.

Üretim kaynak ve imkânlarının yetersiz bulunduğu durumda, birleştirilmiş bulut üretimin içerisindeki üretim bulutları üretim kaynak ve imkânlarını kiralamak için müzakere ve koordinasyon yeteneklerine sahip olmalıdır. Operatörlerin hizmet müşterilerinin bu durumu bilmemesini tercih ettiği ve müşterilerin de bu durumla ilgili rahatsız edilmemeyi istediği ortamda yine de şeffaflık sağlanmalıdır (Yang vd. 2015).

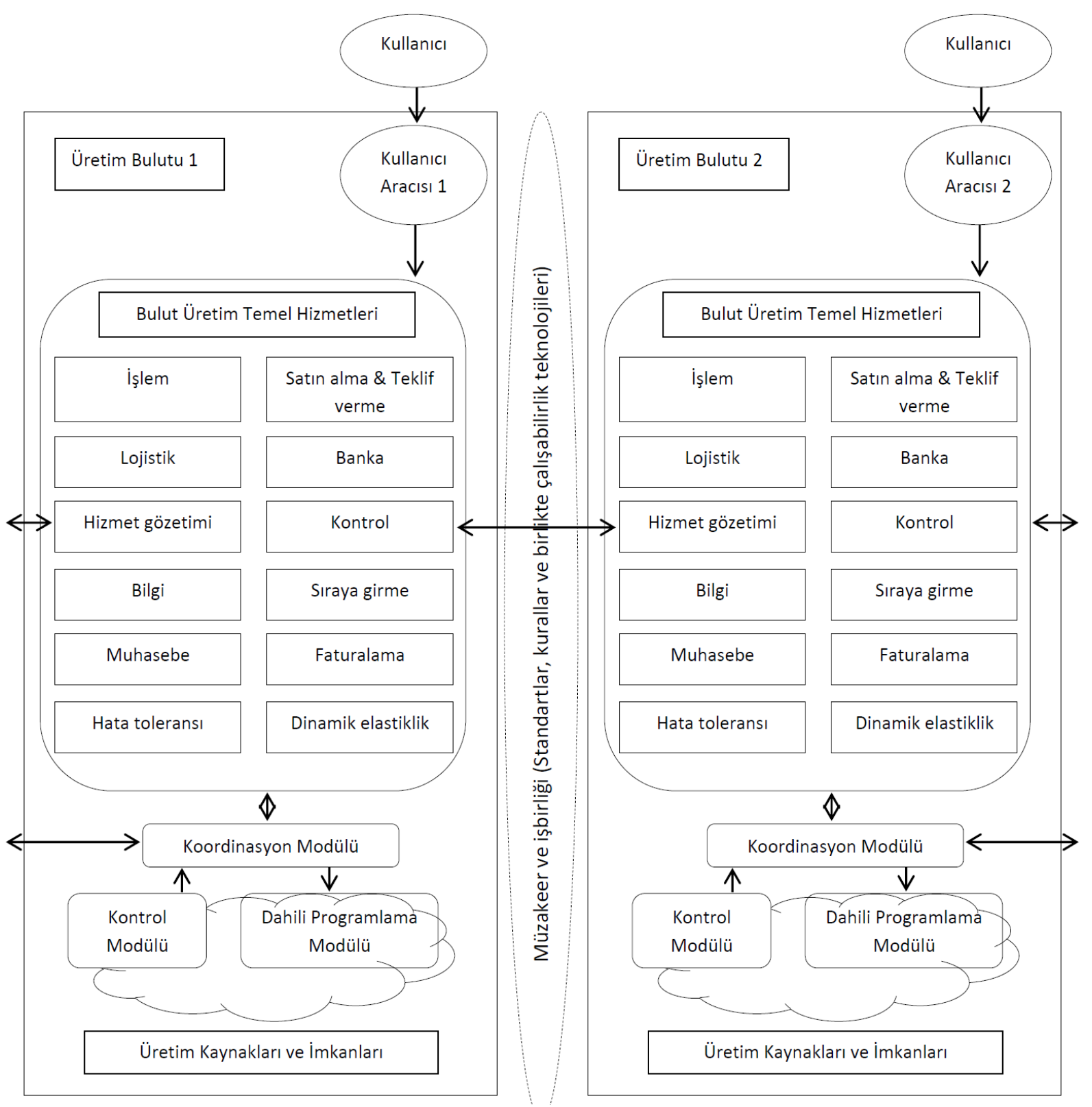

Şekil 4: Birleştirilmiş bulut üretimin altyapısı (Yang vd., 2015) 
Birleștirilmiş bulut üretim modülleri hakkında açıklamalar aşağıdaki gibidir:

Kullanıcı Aracısı: Kullanıcı aracıları hizmet kullanıcılarının yerine karar verip üretim bulutlarıyla müzakereye girerler. Üretim bulutu her kullanıcı için bir aracıyı destekler. Kullanıcı aracısı ilk önce her kullanıcıya göre özelleştirilebilir bir kullanıcı ara yüzü sunar ve kullanıc taleplerini idrak eder. Daha sonra kullanıcıların uygun bulut üretim hizmeti almalarına yardımcı olur.

Bulut Üretim Temel Hizmetleri: Bu modül, işlem, satın alma \& teklif verme, lojistik, banka, hizmet gözetimi, kontrol, bilgi, sıraya girme, muhasebe, faturalama, hata toleransı ve dinamik elastiklik işlemlerinden oluşur.

Koordinasyon Modülü: Koordinasyon modülü farklı üretim bulutlarından seçilmiş olan bulut üretim hizmetlerinin yürütülmesi ile ilgilenir. Bu işlemler uzaktan görev yapabilme için veri dağıtımı, yerel ve/ veya uzaktan sonuç alımı, durum kontrolü veya görev yapma kontrolü işlemlerini içerir.

Kontrol Modülü: Kontrol modülü, üretim kaynak ve imkanlarından belli aralıklarla bilgi toplar ve böylelikle üst katmanlar ne kadar üretim kaynak ve imkanı hizmeti kiralayacağına karar verebilir.

Dahili Programlama Modülü: Dahili programlama modülü üretim kaynak ve imkanlarının paylaşımı ve kontrolü ile ilgilenir. Bu işlemler yapılırken en son sanallaştırma teknolojilerinden yardım alınır. Üretim kaynak ve imkânlarının sanallaştırılması şeffaflık ve esnekliği arttırır ve kullanıcı görevleri için işlemleri daha rahat şekilde yapılabilir hale getirir.

Müzakereler ve İşbirlikleri: Birleştirilmiş üretim bulutları arasındaki müzakereler ve işbirlikleri kurallar, standartlar ve birlikte çalışılabilirlik teknolojileri tarafından desteklenir. Kurallar işbirliği içeriğini ve birleştirilmiş üretim bulutlarının davranış özelliklerini belirler.

\section{2. Üçüncü Parti Bulut Üretim Özellikleri}

Üçüncü parti bulut üretim yaklaşımı bulut üretime üretim süreçlerinde ihtiyaç duyan hizmet kullanıcılarından gelen talepleri karşılamayı amaçlar. Üçüncü parti bulut üretim yaklaşımını yürüten yazılım platformuna üretim bulutu aracısı denir. Temel olarak, üretim bulutu aracısı bulut üretim hizmetleri verisini farklı üretim bulutlarından toplayabilir, bulut üretim hizmetleri ile ilgili faydalı bilgiyi çıkarabilir, farklı ontolojilere göre bulut üretim hizmetlerini sınıflandırabilir ve müşterilerine fonksiyon, ücret, kalite gibi boyutlar açısından en iyi uyan bulut üretim hizmetiyle eşleşmeleri açısından yardımcı olabilir. Bu kavram, üretim bulutunun hizmetlerinin birbiriyle birleştirilmiş olmadığı, en iyi hizmet seçimi planlarının kullanıcı ihtiyaçlarına göre sağlandığı, fakat kullanıcıların gerekli hizmetleri alabilmek için farklı üretim bulutlarıyla çalışması gereken serbest bütünleştirme yaklaşımıdır.

Diğer yandan daha sıkı bir bütünleştirme yaklaşımı, farklı üretim bulutları tarafından sunulan hizmetleri birleştirerek ve düzenleyerek kullanıcılar için tek seferlik bir bulut üretim hizmetini sunabilir. Bu yöntem, bilgi hizmetlerinin yanı sıra, üretim bulutlarından gelen çeşitli bulut üretim hizmetlerini planlamak için iş akışı yönetimine de destek vermektedir.

Her iki durumda da üretim bulutu aracıları hizmet bilgisini veya bulut üretim hizmetlerini kullanarak yeni üretim bulutu geliştirmek yerine var olan üretim bulutları ile müşteri taleplerini tatmin etmeye çalışmaktadırlar (Yang vd. 2015). 


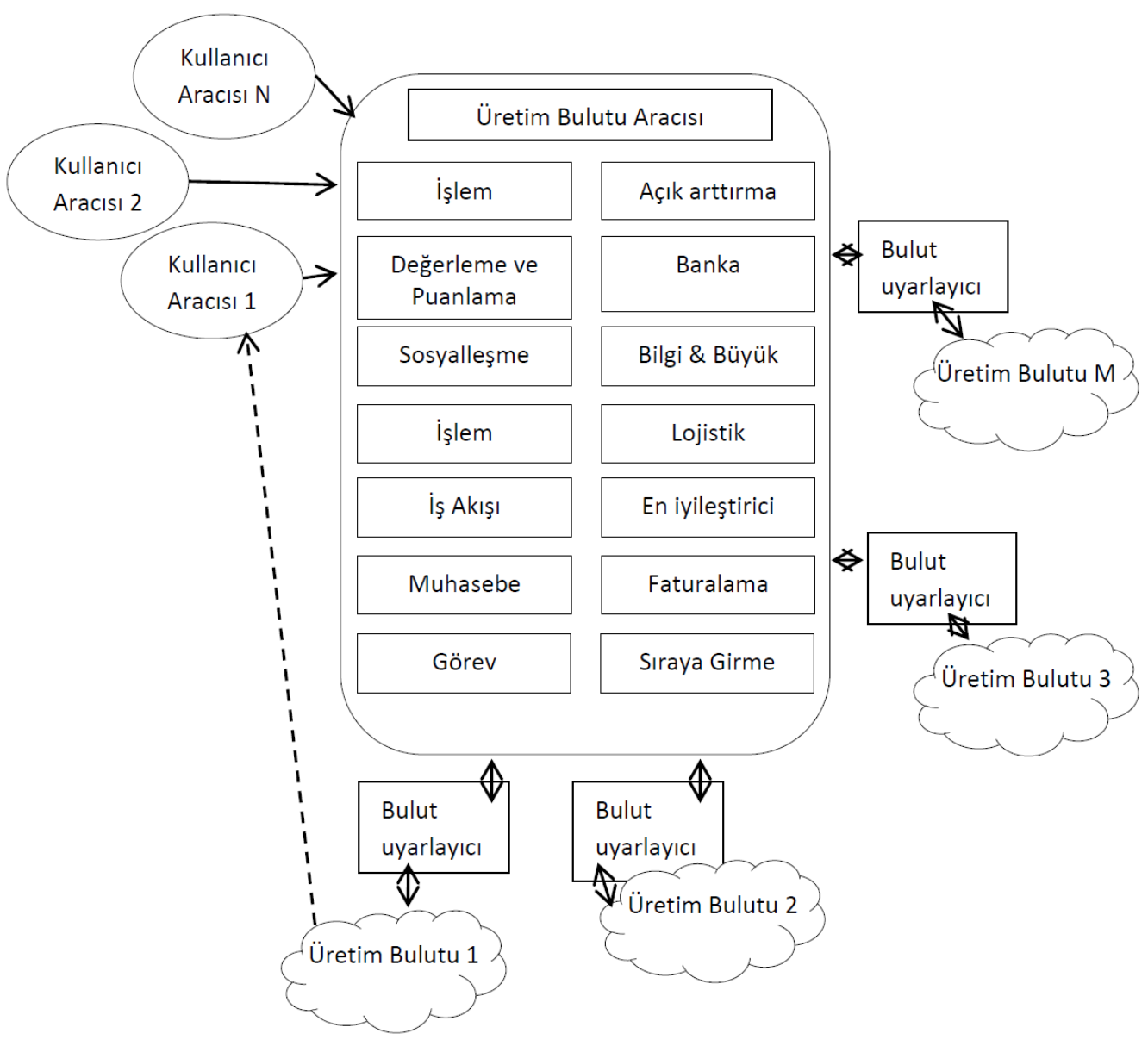

Şekil 5: Üçüncü parti bulut üretimin altyapısı (Yang vd., 2015)

Şekil 5 'te görülebileceği üzere, üretim bulutu aracısı sadece kullanıcı talebi ile hizmet arzı uyduğu sürece hizmet desteği verebilir. Kullanıcılar hizmeti alabilmek için taleplerine uyan üretim bulutlarının kullanıcı ara yüzlerine giriş yapmalılardır.

Kullanıcı Aracısı: Kullanıcı aracısı birleştirilmiş bulut üretim yöntemine benzer fonksiyonları yerine getirmektedir. Yine de durum bazen daha karışık olabilir. Üretim bulutu aracısı sadece bilgilendirme hizmeti sağladığında durum daha karışık olabilir, üretim bulutu aracısı farklı hizmet sağlayıcılar ile müzakere etmeli ve kullanıcı için tatminkâr bir hizmet sunabilmelidir.

Üretim Bulutu Aracısı: Üretim bulutu aracısı temel olarak 14 fonksiyonel modülden oluşmaktadır. Bu modüller şekil 5'te belirtilmiştir.

Bulut Uyarlayıcı: Birleştirilmiş bulut üretim yaklaşımı ile en büyük fark üretim bulutlarının farklı bulut uyarlayıcıları ile üçüncü parti bulut üretime bağlanmasıdır. Üretim bulutları alım satım ile pasif olarak etkileşimde olup bu durumdan dolayı gerekli ara yüz mevcut olmayabilir. Bu sebepten dolayı bulut uyarlayıcıları farklı kullanıcılar ve üretim bulutları arasındaki boşluğu doldurur.

\section{BULUT ÜRETIM ÜZERINE YENI BIR IŞLETME MODELI}

Bulut Üretim müşteri odaklı bir üretim modeli olup paylaşıma açık, çeşitli üretim kaynaklarını geçici olarak kullanıcıya sunabilecek, üretim maliyetini düşürebilecek ve en iyi şekilde kaynak atamasını yapabilecek, talebe göre değişkenlik sağlayan bir görevlendirme sistemidir. Tapscott ve Williams'ın (2008) da belirttiği üzere işletmelerde yenilikçi işletme modellerine ihtiyaç vardır ve bu bölümde işletmelere süreçte yol haritası çizecek bir model önerilmiştir.

Klasik üretim süreci ve Bulut Bilişim kullanımının birleştirilmesi olarak ortaya konulan Bulut Üretim'in altyapısı genel hatlarıyla çalışmanın yukardaki kısımlarında sunulmuştur. Çalışmanın bu kısmında Bulut üretim altyapısı Porter'ın Değer Zinciri modeliyle birleştirilerek yeni bir işletme modeli sunulmuştur. Bu modelde, yukarıda da anlatıldığı şekilde 3 adet 
kullanıcı bulunmaktadır (Xu, 2011). Bunlar: Kaynak kullanıcıları, tedarikçiler ve sistemde kullanıcının talebi ile tedarikçinin sunduğu kaynakları birleştirip aracı görevi yapan operatörlerdir.

Değer Zinciri ile birlikte gösterilen modelde üst katman Bulut üzerindeki uygulama sağlayıcıların, alt katman ise üretim kaynaklarının bulunduğu katman olarak kabul edilmiştir. En altta ise değer zincirinin temel faaliyetleri gösterilmiştir. Kaynak Yönetimi ve Kaynak Sağlama değer zincirinin "iç Lojistik", İşlemler Yönetimi ve Üretim Süreci “işlemler", Stok Yönetimi ve Ürün Depolama “Dış Lojistik", Satış Yönetimi ise "Satış" fonksiyonuna tekabül etmektedir. Çalışma işlemler yönetimi alanına odaklandığı için değer zincirinin son üyesi olan "Müşteri Hizmetleri" kısmı göz ardı edilmiştir.

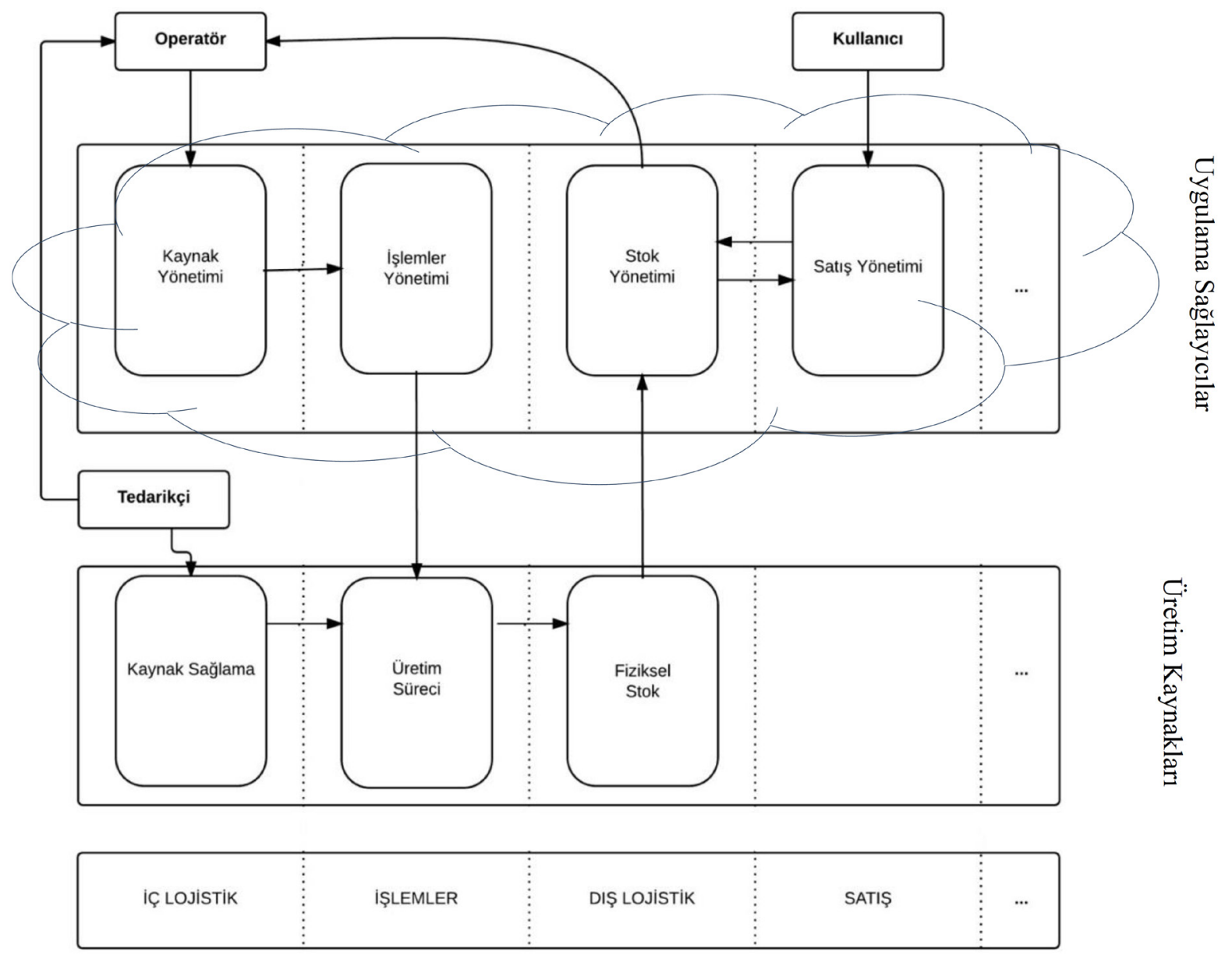

Şekil 5: Bulut Üretim Modeli - İlk Seviye Veri Akış Diyagramı

Yukarıdaki veri akış diyagramında da gösterildiği gibi sistemin 3 adet kullanıcısı bulunmaktadır. Kaynak kullanıcısı ilk önce satış yönetimi sistemine girerek siparişte bulunur, eğer sipariş edilen ürün stokta yoksa sipariş Operatör'e gider. Aynı anda tedarikçinin sağladığı kaynakların bilgisi de (Fiziksel - Fiziksel olmayan kaynaklar) Operatör'e gitmektedir. Operatör kaynak yönetimi sistemini kullanarak müşteriden gelen talepleri tedarikçilerin sağladığı kaynaklarla eşleştirmekte ve en uygun çözümü bulmaktadır. Daha sonra bu bilgi işlemler yönetimi modülüne aktarılmaktadır. İşlemler Yönetimi sürecinden geçildikten sonra üretim sürecinin başlaması için izin verilir. Üretim çıktıları dış lojistik tarafında fiziksel olarak depolanmaktadır ve adet miktarı Stok Yönetimi programına girilerek veritabanı güncellenmektedir. En son olarak müşteriye istemiş bulunduğu ürün ulaştırılır. 


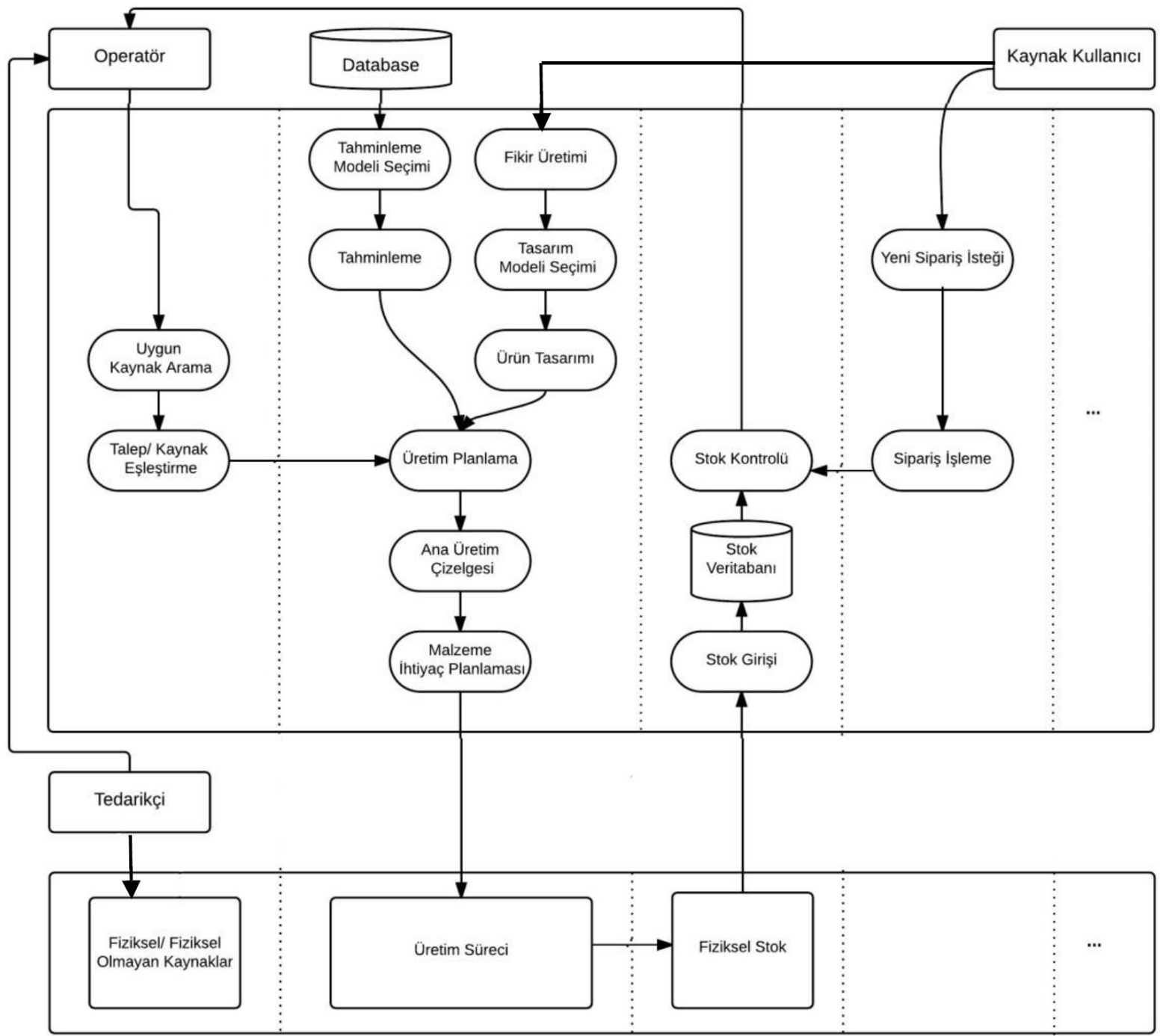

Şekil 6: Bulut Üretim Modeli - Ikinci Seviye Veri Akış Diyagramı

İkinci seviye veri akış diyagramında Uygulama Sağlayıcı katmanı bir seviye daha ayrıntılandııımıştır. Uygun Kaynak Arama ve Talep/ Kaynak Eşleştirme modülleri Kaynak Yönetimini oluşturur, operatör aldığı talep ve kaynak bilgilerini burada kullanıp talebe en iyi şekilde karşııık verebilecek kaynakları seçer. Bu eşleştirme Üretim Planlamanın bir girdisi olur. Üretim planlamanın diğer iki girdisi ise tahminleme sonuçları ve ürün tasarımıdır. Tahminlemeden önce ilgili veri toplanır, bulutta seçilen tahminleme modeline bu veriler girilir ve tahminleme sonuçları ortaya çıkar. Ürün tasarımı ise Kaynak Kullanıcıların yarattığı fikirlerin sonucu olarak ortaya konmaktadır. Üretim planlaması hazırlandıktan sonra Ana Üretim Çizelgesi ve Malzeme ìntiyaç Planlaması da hazırlanarak Üretim süreci başlatılır. Fiziksel üretim Üretim Kaynakları Katmanındaki kaynakların kullanımı ile gerçekleşir. Daha sonra üretilen bu ürünler depolanır. Bulutta bulunan stok sisteminde yeni üretilen ürünler ile ilgili sürekli olarak güncelleme yapılmalıdır. En son olarak üretilen ürünler müşteriye ulaştırılır.

\section{SONUÇLAR}

Gelişen teknolojinin klasik üretim süreçlerine etki etmeye başladığı günümüzde gözlenmektedir. En güncel teknolojilerden biri olan Bulut Bilişim, klasik üretim süreciyle birleştiğinde ağ tabanlı üretim ailesine Bulut Üretim kavramını katmaktadır. Bulut Üretim kavramı altyapı olarak Bulut Bilişim, Nesnelerin Interneti (IoT), gelişmiş hesaplama, sanallaştırma ve hizmet odaklı teknolojileri kullanmakta ve diğer gelişmiş üretim sistemlerinden de destek almaktadır. Bu çalışmada Bulut Bilişim ve Bulut Üretimin altyapıları incelenmiş, bulut üretim kullanımının işletmelere sağlayacağı avantaj ve dezavantajlar belirtilmiş, bulut üretim süreçlerinde güncel bir konu olan farklı üretim 
bulutlarının birleştirilmesi konusuna değinilmiştir. Son olarak, işletmelerin Bulut Üretim'i kullanmaya başladıklarında izleyecekleri mantıksal süreç veri akış diyagramlarıyla gösterilmiştir. Çalışmada anlatılan model kaynak kullanımını en iyileştirme ve kaynak ve enerji tüketimini azaltma odaklıdır. Bu modelin kullanımıyla birlikte işletmeler paylaşım ve işbirliğini arttırabilecek, üretim odaklı üretim modelinden hizmet odaklı üretim modeline geçebilecekler, bu sayede rekabetçi avantajlarını arttırabileceklerdir.

\section{KAYNAKLAR}

Armbrust, M., Fox, A., Griffith, R., Joseph, A. D., Katz, R., Konwinski, A., Lee, G., Patterson, D., Rabkin, A., Stoica, I. ve Zaharia, M. (2010) "A view of cloud computing" Commun ACM 53(4):50-58

Bughin, J., Chui, M. ve Manyika, J. (2010) "Big data, and smart assets: ten tech enabled business trends to watch.” McKinsey Quarterly McKinsey Global Institute

Epicor (2013). "End-to-end on-Demand ERP Solution for Manufacturers." Available online: http://www. epicor.com/Cloud/Pages/Cloud-Manufacturing.aspx

Fielding, RT., (2010) The REpresentational State Transfer. PhD dissertation. Irvine: Department of Information and Computer Science, University of California. Available online at: /http://www.ics.uci.edu/ fielding/ pubs/disser tation/top.htmS

Hao, Q., Shen, W. ve Wang, L. (2005) "Towards a Cooperative Distributed Manufacturing Management Framework." Computers in Industry 56 (1): 71-84.

$\mathrm{He}, \mathrm{W}$. ve Xu, L. (2015) "A state-of-the-art survey of cloud manufacturing." Int J Comput Integr Manuf 28(3):239-250

Huang, GQ., Zhang, YF., Jiang, PY. (2007) "RFIDbased wireless manufacturing for walking- worker assembly islands with fixed-position layouts." International Journal of Robotics and Computer Integrated Manufacture;23(4):469-77.

Huang, GQ., Wright, PK. ve Newman ST. (2009) "Wireless Manufacturing: A Literature Review, Recent Developments, And Case Studies". International Journal of Computer Integrated Manufacturing 22.7: 579-594. Web.

Kirkham, T., Armstrong, D., Djemame, K. ve Jiang, M. (2014) "Risk driven Smart Home resource management using cloud services." Futur Gener Comput Syst 38:13-22

Li, BH., Zhang, L., Wang, SL., Tao, F., Cao, JW., Jiang, XD., Song, X. ve Chai XD. (2010) "Cloud manufacturing: a new service-oriented networked manufacturing model." Computer Integrated Manufacturing Systems CIMS; 16(1): 1-7.

Lu, Y., Xu, X. ve Xu, J. (2014) "Development of a hybrid manufacturing cloud" J Manuf Syst 33(4):551-566
Mell, P. ve Grance, T. (2009) "Perspectives on cloud computing and standards." National Institute of Standards and Technology (NIST). Information Technology Laboratory.

Pallis G. (2010) "Cloud computing: the new frontier of internet computing" IEEE Internet Computing [14:5:5562494:70-73].

Tao F, Hu YF ve Zhang L. (2010), “Theory and practice: optimal resource service allocation in manufacturing grid." Beijing:ChinaMachinePress.

Tao, F., Zhang, L., Venkatesh, V. C., Luo, Y. ve Cheng, Y. (2011) Cloud manufacturing: a computing and service oriented manufacturing model, Proc. IMechE Vol. 225 Part B: J. Engineering Manufacture: 1969-1976.

Tapscott D., Williams AD.. (2008), "Wikinomics: the art and science of peer production", Wikinomics: how mass collaboration changes everything. USA: PenguinGroup Inc.; p. 7-33.

The Open Group, Service Oriented Architecture (SOA), 2010. Available online at: /http://www.opengroup. org/projects/soa/S.

Xu, X., (2011). "From Cloud Computing to Cloud Manufacturing." Robotics and Computer-Integrated Manufacturing 28: 75-86.

Wang XV ve Xu XW (2013) "ICMS: a cloud-based manufacturing system.” In: Li W, Mehnen J (eds) Cloud manufacturing. Springer-Verlag, London, pp 1-22

Wu, D., Greer, M. J., Rosen, D. W. ve Schaefer, D (2013) "Cloud manufacturing: Strategic vision and state-of-the-art", Journal of Manufacturing Systems. 32, 564- 579

Valilai, OF ve Houshmand, M. (2013) "A Collaborative and Integrated Platform to Support Distributed Manufacturing System Using a Service-Oriented Approach Based on Cloud Computing Paradigm." Robot Comput Integr Manuf 29(1):110-127

Yang, H. W. (2010) "Cloud Manufacturing: A Manufacturing Service”, Manufacture Information Engineering of China 3: 22-23.

Yang, C., Shen, W., Lin, T. ve Wang, X. (2015)"A Hybrid Framework For Integrating Multiple Manufacturing Clouds". The International Journal of Advanced Manufacturing Technology 86.1-4: 895-911 
Zhang, L., Guo, H., Tao, F., Luo, Y.L. ve Si, N. (2010) "Flexible Management of Resource Service Composition in Cloud Manufacturing." Proceedings of the IEEE IEEM: 2278 - 2282 
